\title{
Update on twice-daily bromfenac sodium sesquihydrate to treat postoperative ocular inflammation following cataract extraction
}

This article was published in the following Dove Press journal:

Clinical Ophthalmology

26 April 2012

Number of times this article has been viewed

Ester Carreño'

Alejandro Portero 2

David J Galarreta 1,3

José M Herreras ${ }^{1,3}$

'Ocular Immunology Unit-IOBA

(Instituto Universitario de

Oftalmobiología), University of

Valladolid, Campus Miguel Delibes,

Valladolid, Spain; ${ }^{2}$ Ocular Immunology

Unit, Hospital La Zarzuela, Madrid,

Spain; ${ }^{3}$ Ocular Immunology Unit,

Hospital Clínico Universitario de

Valladolid, Valladolid, Spain
Correspondence: Ester Carreño Institute of Applied Ophthalmobiology, University of Valladolid, Campus Miguel Delibes, Valladolid E-470 II, Spain

Tel +34 983186369

Fax +34983 I84762

Email estherc@ioba.med.uva.es
Abstract: Ophthalmic bromfenac sodium sesquihydrate is a topically applied selective cyclooxygenase (COX)-2 inhibitor. It is similar to amfenac, except for a bromine atom at the $\mathrm{C}_{4}$ of the benzoyl ring position, which markedly affects its in vitro and in vivo potency, extends the duration of anti-inflammatory activity, and enhances its inhibitory effect on COX-2 absorption across the cornea and penetration into ocular tissues. The United States Food and Drug Administration approved bromfenac in 2005 for the treatment of postoperative inflammation and the reduction of ocular pain in patients who have undergone cataract surgery. Nonsteroidal anti-inflammatory drugs (NSAIDs), and among them bromfenac, could be even more effective than steroids at reestablishing the blood-aqueous barrier, as revealed by flare on slit-lamp examination and as quantitatively measured using ocular fluorophotometry. Similar to other NSAIDs, it has a role in inhibiting intraoperative miosis during cataract surgery. However, bromfenac also seems to be useful in other situations, such as refractive surgery, allergic conjunctivitis (not useful in dry eye), choroidal neovascularization, and even ocular oncology. No reports of systemic toxicity have been published and bromfenac has good topical tolerance with a low incidence of adverse effects.

Keywords: bromfenac, ophthalmic nonsteroidal anti-inflammatory drugs, inflammation, cataract surgery

\section{Bromfenac sodium sesquihydrate Molecule}

Bromfenac sodium sesquihydrate, also denominated as sodium 2-amino-3-(4bromobenzoyl) phenylacetate sesquihydrate, has a molecular weight of 766.34 and a molecular formula of $\mathrm{C}_{30} \mathrm{H}_{28} \mathrm{Br}_{2} \mathrm{~N}_{2} \mathrm{Na}_{2} \mathrm{O}_{9}$ (Figure 1). The chemical structure is similar to amfenac, except for the addition of a bromine atom at the $\mathrm{C}_{4}$ of the benzoyl ring position. Containing a halogen in its structure enhances the molecule's lipophilicity, thereby facilitating absorption across ocular tissues. The bromine atom of bromfenac has a marked effect on its in vitro and in vivo potency, extends the duration of antiinflammatory activity, and enhances its inhibitory effect on cyclooxygenase (COX)-2 absorption across the cornea and penetration into ocular tissues. ${ }^{1,2}$

\section{Mechanism of action}

Bromfenac, a nonsteroidal anti-inflammatory drug (NSAID), has anti-inflammatory activity thought to be due to its ability to block prostaglandin synthesis by inhibiting COXs, an important group of enzymes active in the inflammatory process, which catalyzes the biosynthesis of eicosanoids from arachidonic acid to produce 


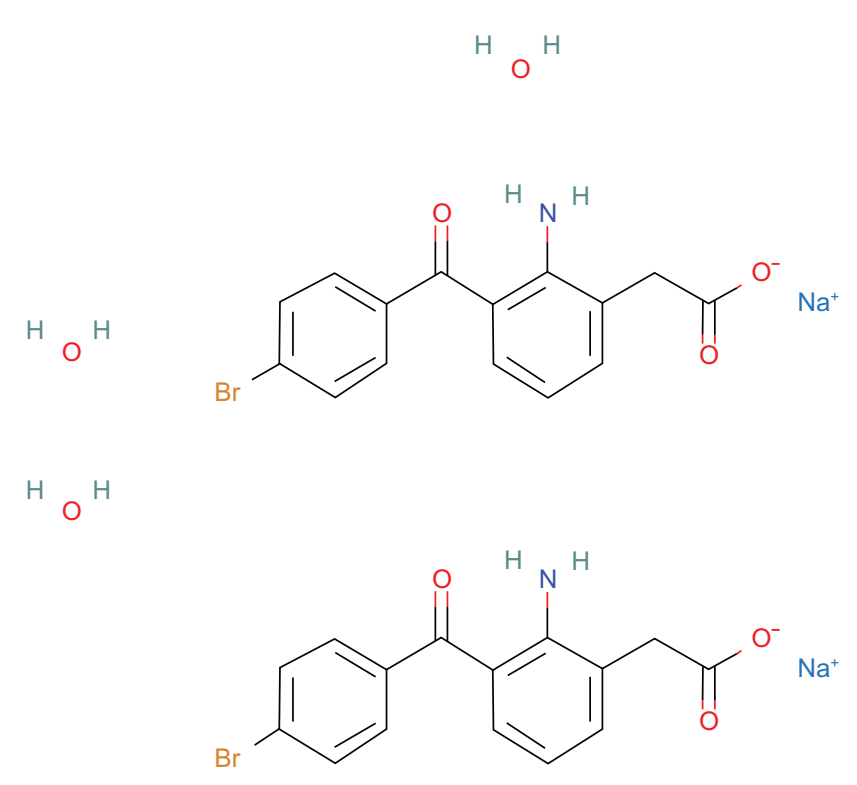

Figure I Molecular structure of bromfenac sodium sesquihydrate.

prostaglandins (PG) and thromboxanes. ${ }^{1}$ Prostaglandins are mediators of certain kinds of intraocular inflammation. In studies of animal eyes, PG have been shown to disrupt the blood-aqueous humor barrier and increase vascular permeability, vasodilatation, intraocular pressure, and leukocytosis. ${ }^{3,4}$

Two cyclooxygenases (COX-1 and COX-2) encoded by two different genes have been cloned and characterized. ${ }^{5,6}$ Although COX-1 and COX-2 share a high level of homology $(65 \%)$, the activity and expression of these enzymes are regulated differentially, and they can function independently within the same cell type. ${ }^{7} \mathrm{COX}-1$ is important for homeostatic functions, such as maintaining the integrity of the gastrointestinal mucosa, mediating platelet function, and regulating renal blood flow. COX-2 is often induced at sites of inflammation. Animal models have shown that COX-2 is the primary mediator for ocular inflammation. ${ }^{3}$ Therefore, inhibition of COX-2 is thought to be the most important therapeutic mechanism of ophthalmic NSAIDs.

NSAIDs have different relative potencies against COX-1 and COX-2. Bromfenac has been shown to be the most potent ophthalmic NSAID in inhibiting the COX-2 enzyme. ${ }^{4}$ It was approximately 32 times more active against COX-2 than COX-1 in a rabbit model and 18 times more potent than ketorolac in inhibiting COX-2. ${ }^{8}$

\section{Ocular pharmacokinetics}

The plasma concentration of bromfenac following ocular administration of bromfenac $0.09 \%$ ophthalmic solution in humans is unknown. Based on the maximum proposed dose of one drop in each eye $(0.09 \mathrm{mg})$ and pharmacokinetic information from other routes of administration, the systemic concentration of bromfenac is estimated to be below the limit of quantification $(50 \mathrm{ng} / \mathrm{mL})$ at steady-state in humans. ${ }^{9}$

Studies evaluating the pharmacokinetic profile of topical bromfenac $0.09 \%$ revealed a maximum concentration of $95.3 \mathrm{ng} / \mathrm{g}$ in the aqueous humor after instillation of a single dose in rabbits. ${ }^{10}$ The time to maximum concentration in the aqueous humor in both studies was 2 hours. ${ }^{10,11}$ The half-life was 2.2 hours, but the drug remained detectable at 24 hours. ${ }^{10,11}$ In a separate multi-dose study, rabbits received one drop of bromfenac $0.09 \%$ three times daily for 14 days. The bromfenac concentration was $1103.0 \pm 424.2 \mathrm{ng} / \mathrm{g}$ in the sclera; $78.1 \pm 13.0 \mathrm{ng} / \mathrm{g}$ in the choroid; $32.4 \pm 5.4 \mathrm{ng} / \mathrm{g}$ in the retina; $1.3 \pm 0.2 \mathrm{ng} / \mathrm{g}$ in the vitreous; and $55.9 \pm 9.2 \mathrm{ng} / \mathrm{g}$ in the aqueous humor. ${ }^{10}$

Human studies have revealed that the drug concentration required to reduce human $\mathrm{COX}-2$ activity to half maximal $\left(\mathrm{IC}_{50}\right)$ was achieved after a single dose of bromfenac, ${ }^{12}$ and the concentration of bromfenac in the aqueous humor of patients undergoing cataract surgery, after the instillation of one drop of bromfenac 12 hours prior to surgery, was in excess of the $\mathrm{IC}_{50}$ value for COX-2, but not the $\mathrm{IC}_{50}$ value for COX $-1 .^{13}$

\section{Ocular commercial presentations}

Bromfenac sodium ophthalmic solution $0.1 \%$ was first approved in 2000 as Bronuck $^{\circledR}$ (Senju Pharmaceutical Company, Ltd, Osaka, Japan) and is currently approved for the clinical indications of the treatment of postoperative inflammation, blepharitis, conjunctivitis, and scleritis. ${ }^{14}$ The same formulation was approved in the United States in 2005 as Xibrom ${ }^{\mathrm{TM}} 0.09 \%$ (Ista Pharmaceuticals Inc, Irvine, CA) for the treatment of postoperative inflammation and the reduction of ocular pain in patients who have undergone cataract surgery. However, it has been unavailable since February $2011^{9}$ because in October 2010, Bromday ${ }^{\mathrm{TM}}$ 0.09\% (Ista Pharmaceuticals Inc) was approved by the Food and Drug Administration (FDA) as the first once-daily ophthalmic NSAID for the treatment of postoperative ocular inflammation and the reduction of ocular pain after cataract surgery. ${ }^{15}$ A generic formulation in 2011 was approved in the United States by Coastal Pharms. In Europe, Yellox ${ }^{\mathrm{TM}} 0.09 \%$ (Croma Pharma, GmbH, Leobendorf, Austria) was approved in 2011 for the treatment of postoperative ocular inflammation following cataract extraction in adults. ${ }^{16}$ 


\section{Once-daily dose}

Several studies have found that ophthalmic medications dosed less frequently tend to yield improved compliance and patient satisfaction. ${ }^{17}$ The benefits of less frequent dosing also include less exposure to benzalkonium chloride and a lower potential for adverse effects. ${ }^{18,19}$

Based on previous studies, which showed detectable concentrations of bromfenac at 24 hours after a single dose, ${ }^{10-12}$ the possibility of bromfenac $0.09 \%$ dosed once daily was studied.

Overall, bromfenac ophthalmic solution $0.09 \%$ dosed once a day appeared to be as effective as when dosed twice a day in treating post-cataract surgery anterior chamber inflammation, although no direct comparisons were made and the designs of the clinical trials were different. ${ }^{20,21}$ However, there are no studies determining the efficacy of once-daily doses in the treatment of posterior segment inflammation.

\section{Adverse effects of ophthalmic bromfenac \\ Systemic adverse effects}

Oral bromfenac was initially approved for the treatment of short-term pain in 1997.22 However, cases of fulminant hepatic failure were reported after prolonged use, and it was withdrawn from the market in $1998 .^{23,24}$ Although the plasma concentration of bromfenac following ocular administration of bromfenac $0.09 \%$ ophthalmic solution in humans is unknown, it is supposed to be below the limit of quantification $(50 \mathrm{ng} / \mathrm{mL})$ and no reports of systemic toxicity have been published. ${ }^{9}$

Shiffman et $\mathrm{al}^{25}$ also confirmed the systemic safety. They showed normal liver function test values for more than $90 \%$ of subjects and no evidence of hepatic toxicity after 14 days of twice-daily dosing of topical bromfenac. ${ }^{18}$

Although exacerbation of asthmatic symptoms has been reported with the use of topical NSAIDs, such as diclofenac or indomethacin, these events have not been described with the use of topical bromfenac. ${ }^{26,27}$

\section{Ocular adverse effects}

The rate of serious ocular adverse events, reported 6 years after the use of topical bromfenac in one study, was $0.0002 \%{ }^{18}$ These serious ocular adverse events included five corneal ulcers, three corneal erosions, three corneal perforations, three corneal infiltrates, and two cases of corneal thinning. ${ }^{18}$ The most commonly reported adverse effects in the Phase III clinical trials of topical bromfenac included iritis, an abnormal sensation in the eye, eye pain, eye pruritus, headache, eye irritation (burning/stinging), and conjunctival hyperemia. ${ }^{18}$

The adverse effects of bromfenac eye drops in the ocular surface have been described as being particularly associated with the preservatives used in ophthalmic solutions, such as benzalkonium chloride. However, the experimental use of preservative-free bromfenac (commercially unavailable) also exhibited considerable toxicity in corneoconjunctival cell lines. ${ }^{28}$ In contrast, in Phase III clinical trials of topical bromfenac, safety assessments for subjects treated with bromfenac were generally equivalent to or better than those for subjects treated with a vehicle. ${ }^{18}$ Animal studies have implicated NSAIDs in delaying corneal wound healing ${ }^{29}$ and decreasing the migration of corneal epithelium. ${ }^{30}$ There are four reported cases of corneal melting and subsequent perforation in one of them after topical bromfenac use. ${ }^{31,32}$ In three of the reported cases of bromfenac-induced melting, the patients had severe ocular surface compromise. A role for metalloproteinase (MMP)-1 and MMP-8 has been proposed in NSAID-induced melting. An increase in MMP-1 and MMP-8 expression in eyes treated with diclofenac has been reported. ${ }^{33}$ Proteases play an important role in corneal degradation and NSAID use may be implicated in their overexpression.

One study assessed the effects of topical bromfenac in human corneal endothelial cells, and revealed it was unlikely to cause endothelium damage at the concentration used under the usual conditions. ${ }^{28}$

\section{Bromfenac in cataract surgery}

NSAIDs are one of the most commonly prescribed classes of medications worldwide. Aspirin and other chemically related compounds, the properties of which in oral presentations have been well known for many decades, have recently been prepared in topical ophthalmic formulations. Systemic indications are due to their analgesic, antipyretic, and antiinflammatory properties.

In the United States, bromfenac ophthalmic solution $0.09 \%$ (Xibrom $^{\mathrm{TM}}$; Ista Pharmaceuticals Inc) was approved by the US Food and Drug Administration (FDA) in 2005 for the treatment of postoperative inflammation and the reduction of ocular pain in patients who have undergone cataract surgery. ${ }^{9}$

\section{Mydriasis maintenance during surgery}

Topical NSAIDs are FDA-approved for the inhibition of intraoperative miosis during cataract surgery. Several clinical studies have demonstrated similar mydriatic properties for 
diclofenac $0.1 \%,{ }^{34,35}$ ketorolac $0.4 \%$ and $0.5 \%,{ }^{36,37}$ suprofen $1 \%,{ }^{38,39}$ flurbiprofen $0.03 \%,{ }^{35}$ and bromfenac $0.09 \% .^{40}$ However, the effectiveness of topical NSAIDs on pupil size in vitreoretinal surgery appears to vary from one study to another. ${ }^{39}$

\section{Reducing postoperative inflammation in cataract surgery}

There is evidence that topical NSAIDs are capable of reducing postoperative inflammation after cataract surgery ${ }^{38,39}$ when used correctly and cause no significant side effects or toxicity. ${ }^{41-44}$ However, there are only four FDA-approved drugs for this use: diclofenac, ketorolac, nepafenac, and bromfenac. Although studies comparing NSAIDs to corticosteroids have not revealed differences in the reduction of intraocular inflammation after cataract surgery, ${ }^{42,45-47}$ NSAIDs appear to be more effective at reestablishing the blood-aqueous barrier, as revealed by flare on slit-lamp examination and as quantitatively measured using ocular fluorophotometry. ${ }^{38,39,42,48}$ This is true for both bromfenac presentations currently available in the USA. ${ }^{20,21,40,49,50}$ Bromfenac has not been demonstrated to be superior to ketorolac in reducing the inflammation rate, but the incidence of corneal epitheliopathy was reported to be significantly higher. ${ }^{18}$ Takamatsu et al and Ohara et al's case series comparing bromfenac and diclofenac drops after cataract extraction did not show any differences in the inflammation rate on days 7 and 28 , respectively. ${ }^{51,52}$

Masuda et al compared several concentrations of twicedaily $0.01 \%, 0.1 \%$, and $0.2 \%$ bromfenac drops in 228 cataract cases. The $0.1 \%$ and $0.2 \%$ solutions showed superior antiinflammatory activity in contrast to the $0.01 \%$ solution. There were no adverse events that were concentration-dependent; thus, $0.1 \%$ bromfenac was deemed optimal to minimize any potential for corneal toxicity. ${ }^{53}$

Both once- and twice-daily dosing of bromfenac have been demonstrated to be beneficial for patients with a low rate of compliance or who need to minimize exposure to medications and excipients. ${ }^{18,20}$ However, efficacy data from clinical trials of bromfenac $0.09 \%$ with once-daily dosing cannot be directly compared to twice-daily dosing because the protocols for these clinical trials differ in terms of the predosing criteria and the Summed Ocular Inflammation Score (SOIS) end point scales used. ${ }^{21}$ Both dosing presentations achieved the prespecified efficacy end points of their respective clinical trials and were thus effective in comparison to the placebo group.

Miyanaga et al compared topical bromfenac to a topical steroid or a combination in 72 patients following cataract surgery. ${ }^{54}$ They did not find any significant difference in anterior chamber inflammation in this case series. There is no recent larger controlled trial comparing the efficacy of bromfenac alone versus a steroid or a combination in cataract surgery. There are no publications about using bromfenac in glaucoma, strabismus, or vitreoretinal surgeries to reduce inflammation.

\section{Reducing ocular pain in cataract surgery}

Among subjects who experienced ocular pain after surgery, the median time for resolution of pain was 2 days for those treated with bromfenac compared with 5 days for those treated with a vehicle. The proportion of subjects who were pain-free was statistically significantly greater for the bromfenac group than for the vehicle group over all visits. ${ }^{55,56}$ In January 2006, the FDA expanded the indication for bromfenac to include the reduction of ocular pain after cataract surgery on the basis of these results.

\section{Cystoid macular edema}

Cystoid macular edema (CME) remains the most common cause of vision loss after cataract surgery, with up to $58 \%$ of patients being reported to have some angiographic evidence of CME. ${ }^{57}$ On the other hand, the rate of clinically evident CME was much lower at $4.7 \%$ in those treated with a placebo and $1.8 \%$ in those treated with steroids. ${ }^{18}$ Currently, there is no FDA-approved treatment for the prevention or treatment of CME following cataract surgery. However, reviewing the world literature, Rossetti et al determined from a meta-analysis that the prevention and treatment of CME with NSAIDs is beneficial. ${ }^{58}$

It remains unclear whether prophylactic treatment prevents the onset of chronic CME or in some way decreases its severity. Therefore, the long-term benefit of prophylactic treatment remains unproven, making this FDA-unapproved indication controversial..$^{59}$

\section{Other ophthalmic uses of bromfenac}

NSAIDs have increasingly been included in the therapeutic arsenal in ophthalmology. The treatment of intraocular inflammation and pain after cataract surgery and the treatment and prevention of cystoid macular edema are the main indications. However, NSAIDs have also been suggested to have some effectiveness in some pathology, but with a more limited action than other available agents. Their use in these cases can be considered additional therapy.

\section{Allergic conjunctivitis}

The pathogenesis of allergic conjunctivitis is complicated, but the mast cell and its chemical mediators are 
probably the most important components. These mediators comprise a wide range of molecules, including many different PG. Among them, PGE1 and PGE2 diminish the threshold of itching and become NSAIDs in potential therapy for allergic conjunctivitis. Topical ketorolac $0.5 \%$ is the only NSAID approved by the FDA for the relief of ocular itching in patients with seasonal allergic rhinoconjunctivitis.

In an experimental model, Hashimoto et al found that ketotifen was less effective in reducing PG than bromfenac, but it reduced plasma exudation significantly more. Moreover, ketotifen was much more effective in inhibiting the itch-scratch response than bromfenac. ${ }^{60}$

Miyake-Kashima et al compared bromfenac to the mastcell stabilizer, pemirolast potassium. Improvements in objective clinical findings were similar for both, and subjective symptoms after one week of twice-daily dosing did not show any improvement for either agent. ${ }^{61}$

Uchio et al evaluated the efficacy and safety of bromfenac $0.1 \%$ in the long-term management of vernal keratoconjunctivitis patients while mast cell stabilizers and topical steroids were continued. They found that the role of bromfenac in these patients might be to suppress the trigger-inducing recurrence of the disease by controlling the COX pathways. Once vernal keratoconjunctivitis recurred, bromfenac could not reduce the severity of the disease. ${ }^{62}$

\section{Ocular surface inflammatory diseases}

Oral NSAIDs are used as first-line agents in scleritis and episcleritis with good results. However, topical presentations have not had the same results and are therefore infrequently used. ${ }^{63}$ There is evidence that NSAIDs are more useful in the treatment of inflamed pinguecula and pterygium compared to topical steroids. ${ }^{64}$

\section{Dry eye}

Inflammation was included in the new definition of dry eye given by the International Dry Eye Workshop. ${ }^{65}$ Inflammatory mediators in the dry eye tear film are a potential target for molecules such as NSAIDs with lower side effects than topical corticosteroids. A recent study in a mouse model of dry eye raised the possibility that NSAIDs may help alleviate some of the signs and symptoms of ocular surface disease ${ }^{66}$ However, corneal melting and perforations have been reported with NSAIDs, even with bromfenac, which prevents routine use in dry eye patients for these potential adverse events, especially in cases with corneal involvement. ${ }^{31,67}$

\section{Refractive surgery}

Surface laser procedures remove the corneal epithelium in different ways (laser, manual debridement, diluted alcohol, epikeratome) prior to laser ablation of the stroma. Regardless of which technique is used, laser reshaping of the cornea damages the sensory nociceptive fibers. Patients can experience various degrees of pain during the epithelial regeneration process, and NSAIDs are effective in controlling it. Moreover, they have the additional benefit of reducing inflammation by inhibiting COX. In ophthalmology, the primary topical analgesia used to control pain is NSAIDs and this medication has shown to be effective in photorefractive keratectomy. ${ }^{68,69}$

Sher et al found no significant differences in discomfort and safety between topical bromfenac $0.09 \%$ and ketorolac $0.4 \%$, approved by the FDA to control postoperative photorefractive keratectomy ablation pain. ${ }^{69}$ However, Wang et al found there was less pain in eyes treated with bromfenac $0.09 \%$ than in those treated with ketorolac $0.5 \%$ following LASEK or epi-LASEK surgery. There were no statistically significant differences in uncorrected visual acuity between groups. ${ }^{70}$

\section{Diabetic retinopathy}

Both animal and human studies have demonstrated elevated levels of $\mathrm{PG}$ in eyes with diabetic retinopathy. ${ }^{71,72}$ Therapeutic inhibition of COX-2 in the retina may now be achievable with both topical nepafenac $0.1 \%$ and bromfenac $0.09 \%$. The first one has demonstrated the ability to inhibit diabetes-induced retinal microvascular disease in animal models. ${ }^{73}$ Bromfenac may be as useful as nepafenac in animal models. However, there are no studies in humans and consequently, there is insufficient evidence to recommend the use of NSAIDs as prophylaxis or for primary treatment of diabetic retinopathy or even diabetic macular edema. Furthermore, other routes, including periocular and intravitreal, are currently being investigated to achieve greater therapeutic effects. ${ }^{74,75}$

\section{Age-related macular degeneration}

Age-related macular degeneration is the leading cause of blindness in developed countries. ${ }^{76}$ While the etiology and pathogenesis of this disease are complex and remain poorly understood, there is evidence from human and animal studies that inflammatory and immunological events play a central role. ${ }^{77}$

COX-2 is a promoter of angiogenesis and can be detected in human choroidal neovascular membranes. ${ }^{78}$ Thus, the 
inhibition of COX-2 by NSAIDs reduces vascular endothelial growth factor production and directly inhibits choroidal neovascularization in both trauma-induced and ischemiainduced animal models. ${ }^{74}$ In an experimental model, the use of topical bromfenac led to the translocation of Nrf2 and the induction of the antioxidant protein heme oxygenase (HO-1) in neovascularization lesions. The sizes of lesions were significantly smaller in the group of rats treated with bromfenac, indicating a potential therapeutic effect for intraocular angiogenic diseases. ${ }^{79}$ These findings can justify the results that showed bromfenac worked as an adjunctive therapy to intravitreal ranibizumab in a prospective randomized controlled trial, showing a beneficial effect in the change of macular central thickness. ${ }^{80}$ However, Zweifel et al found no benefit to the addition of topical bromfenac $0.09 \%$ twice daily over 2 months for patients receiving monthly intravitreal antivascular endothelial growth factor; in fact, there was limited response in terms of reducing persistent exudation. ${ }^{81}$

At present, there is insufficient evidence to recommend NSAIDs for prophylaxis or treatment of age-related macular degeneration in human beings.

\section{Ocular tumors}

It is well known that systemic NSAIDs reduce the incidence of colon cancer by $40 \%-50 \%$, and several epidemiological, clinical, and experimental studies have established NSAIDs as promising cancer chemopreventive agents. ${ }^{82,83}$ At the same time, COX-2 expression is increased in both uveal melanoma and retinoblastoma. Some COX-2 inhibitors have been demonstrated in experimental studies to inhibit the proliferation of human retinoblastoma cell lines, limit the progression of uveal melanoma, and increase the radiosensitivity of uveal melanoma. ${ }^{84-87}$ Moreover, COX-2 expression appears to be correlated with tumor malignancy. ${ }^{88}$

Future studies about the therapeutic potential of NSAIDs in the treatment and prevention of ocular tumors are under way.

\section{Method of literature search}

In order to prepare this review, we conducted a Medline and PubMed search of the literature for the period between 2000 and 2011 using the following key words, as well as various combinations of them: bromfenac, Xibrom, ophthalmic NSAIDs. Reference lists from the selected articles were used to obtain further relevant articles not included in the electronic database.

\section{Disclosure}

The authors report no proprietary or commercial interest in any product mentioned or concept discussed in this article.

\section{References}

1. Sancilio LF, Nolan JC, Wagner LE, Ward JW. The analgesic and antiinflammatory activity and pharmacologic properties of bromfenac. Arzneimittelforschung. 1987;37(5):513-519.

2. Ruiz J, Lopez M, Mila J, Lozoya E, Lozano JJ, Pouplana R. QSAR and conformational analysis of the antiinflammatory agent amfenac and analogues. J Comput Aided Mol Des. 1993;7(2):183-198.

3. Oka T, Shearer T, Azuma M. Involvement of cyclooxygenase- 2 in rat models of conjunctivitis. Curr Eye Res. 2004;29(1):27-34.

4. Guex-Crosier Y. Non-steroidal anti-inflammatory drugs and ocular inflammation. Klin Monbl Augenheilkd. 2001;218(5):305-308.

5. Moncada S, Gryglewski R, Bunting S, Vane JR. An enzyme isolated from arteries transforms prostaglandin endoperoxides to an unstable substance that inhibits platelet aggregation. Nature. 1976;263(5579):663-665.

6. O'Banion MK, Winn VD, Young DA. cDNA cloning and functional activity of a glucocorticoid-regulated inflammatory cyclooxygenase. Proc Natl Acad Sci U SA. 1992;89(11):4888-4892.

7. Davidge ST. Prostaglandin H synthase and vascular function. Circ Res. 2001;89(8):650-660.

8. Waterbury LD, Silliman D, Jolas T. Comparison of cyclooxygenase inhibitory activity and ocular anti-inflammatory effects of ketorolac tromethamine and bromfenac sodium. Curr Med Res Opin. 2006;22(6):1133-1140.

9. Xibrom (bromfenac ophthalmic solution) $0.09 \%$ [package insert full prescribing information]. Irvine, CA: Ista Pharmaceuticals; 2008.

10. Si EC, Bowman LM, Hosseini K. Pharmacokinetic comparisons of bromfenac in DuraSite and Xibrom. J Ocul Pharmacol Ther. 2011;27(1):61-66.

11. Baklayan GA, Patterson HM, Song CK, Gow JA, McNamara TR. 24-hour evaluation of the ocular distribution of (14)C-labeled bromfenac following topical instillation into the eyes of New Zealand White rabbits. J Ocul Pharmacol Ther. 2008;24(4):392-398.

12. Miyake K, Ogawa T, Tajika T, Gow JA, McNamara TR. Ocular pharmacokinetics of a single dose of bromfenac sodium ophthalmic solution $0.1 \%$ in human aqueous humor. $J$ Ocul Pharmacol Ther. 2008;24(6):573-578.

13. Bucci FA Jr, Waterbury LD. Comparison of ketorolac $0.4 \%$ and bromfenac $0.09 \%$ at trough dosing: aqueous drug absorption and prostaglandin E2 levels. J Cataract Refract Surg. 2008;34(9): 1509-1512.

14. Bronuck [package insert full prescribing information]. Osaka, Japan: Senju Pharmaceutical Company, Ltd; 2003.

15. Bromday (bromfenac ophthalmic solution) $0.09 \%$ [package insert full prescribing information]. Irvine CA: Ista Pharmaceuticals; 2010.

16. Yellox (bromfenac sodium sesquihydrate) [package insert full prescribing information]. Leobendorf, Austria: Croma Pharma GmbH; 2011.

17. Olthoff CM, Schouten JS, van de Borne BW, Webers CA. Noncompliance with ocular hypotensive treatment in patients with glaucoma or ocular hypertension: an evidence-based review. Ophthalmology. 2005;112(6):953-961.

18. Donnenfeld ED, Donnenfeld A. Global experience with Xibrom (bromfenac ophthalmic solution) $0.09 \%$ : the first twice-daily ophthalmic nonsteroidal anti-inflammatory drug. Int Ophthalmol Clin. 2006;46(4):21-40.

19. Cha SH, Lee JS, Oum BS, Kim CD. Corneal epithelial cellular dysfunction from benzalkonium chloride (BAC) in vitro. Clin Experiment Ophthalmol. 2004;32(2):180-184.

20. Silverstein SM, Cable MG, Sadri E, et al. Once daily dosing of bromfenac ophthalmic solution $0.09 \%$ for postoperative ocular inflammation and pain. Curr Med Res Opin. 2011;27(9):1693-1703. 
21. Henderson BA, Gayton JL, Chandler SP, Gow JA, Klier SM, McNamara TR. Safety and efficacy of bromfenac ophthalmic solution (Bromday) dosed once daily for postoperative ocular inflammation and pain. Ophthalmology. 2011;118(11):2120-2127.

22. Bromfenac marketed for short-term pain relief. Am J Health Syst Pharm. 1997;54(19):2151-2152.

23. Hunter EB, Johnston PE, Tanner G, Pinson CW, Awad JA. Bromfenac (Duract)-associated hepatic failure requiring liver transplantation. Am J Gastroenterol. 1999;94(8):2299-2301.

24. Fontana RJ, McCashland TM, Benner KG, et al. Acute liver failure associated with prolonged use of bromfenac leading to liver transplantation. The Acute Liver Failure Study Group. Liver Transpl Surg. 1999;5(6):480-484.

25. Shiffman ML, Donnenfeld ED, Holland EJ, Grillone LR. Investigation of liver toxicity following topical treatment with Xibromt $0.01 \%$, an NSAID for post-cataract surgery inflammation. Proceedings of the American Society of Cataract \& Refractive Surgery (ASCRS) Meeting. Washington, DC: April 15-20, 2005

26. Sharir M. Exacerbation of asthma by topical diclofenac. Arch Ophthalmol. 1997;115(2):294-295.

27. Polachek J, Shvartzman P. Acute bronchial asthma associated with the administration of ophthalmic indomethacin. Isr J Med Sci. 1996;32(11):1107-1109.

28. Ayaki M, Iwasawa A, Soda M, Yaguchi S, Koide R. Cytotoxicity of five fluoroquinolone and two nonsteroidal anti-inflammatory benzalkonium chloride-free ophthalmic solutions in four corneoconjunctival cell lines. Clin Ophthalmol. 2010;4:1019-1024.

29. Hersh PS, Rice BA, Baer JC, et al. Topical nonsteroidal agents and corneal wound healing. Arch Ophthalmol. 1990;108(4):577-583.

30. Hashizume N, Saika S, Okada Y, Miyamoto T, Shimizu K, Ohnishi Y. Effects of antiinflammatory drugs on migration of the rabbit corneal epithelium. J Cataract Refract Surg. 2001;27(9):1499-1502.

31. Isawi H, Dhaliwal DK. Corneal melting and perforation in Stevens Johnson syndrome following topical bromfenac use. J Cataract Refract Surg. 2007;33(9):1644-1646.

32. Asai T, Nakagami T, Mochizuki M, Hata N, Tsuchiya T, Hotta Y. Three cases of corneal melting after instillation of a new nonsteroidal antiinflammatory drug. Cornea. 2006;25(2):224-227.

33. Reviglio VE, Rana TS, Li QJ, Ashraf MF, Daly MK, O’Brien TP. Effects of topical nonsteroidal antiinflammatory drugs on the expression of matrix metalloproteinases in the cornea. J Cataract Refract Surg. 2003;29(5):989-997.

34. Roberts CW. Comparison of diclofenac sodium and flurbiprofen for inhibition of surgically induced miosis. J Cataract Refract Surg. 1996;22 Suppl 1:780-787.

35. Thaller VT, Kulshrestha MK, Bell K. The effect of pre-operative topical flurbiprofen or diclofenac on pupil dilatation. Eye (Lond). 2000;14(Pt 4): 642-645.

36. Donnenfeld ED, Perry HD, Wittpenn JR, Solomon R, Nattis A, Chou T. Preoperative ketorolac tromethamine $0.4 \%$ in phacoemulsification outcomes: pharmacokinetic-response curve. J Cataract Refract Surg. 2006;32(9):1474-1482.

37. Solomon KD, Turkalj JW, Whiteside SB, Stewart JA, Apple DJ. Topical $0.5 \%$ ketorolac vs $0.03 \%$ flurbiprofen for inhibition of miosis during cataract surgery. Arch Ophthalmol. 1997;115(9):1119-1122.

38. Flach AJ. Topical nonsteroidal antiinflammatory drugs in ophthalmology. Int Ophthalmol Clin. 2002;42(1):1-11.

39. Flach AJ. Cyclo-oxygenase inhibitors in ophthalmology. Surv Ophthalmol. 1992;36(4):259-284.

40. Jones J, Francis P. Ophthalmic utility of topical bromfenac, a twicedaily nonsteroidal anti-inflammatory agent. Expert Opin Pharmacother. 2009;10(14):2379-2385.

41. Flach AJ, Graham J, Kruger LP, Stegman RC, Tanenbaum L. Quantitative assessment of postsurgical breakdown of the blood-aqueous barrier following administration of $0.5 \%$ ketorolac tromethamine solution. A double-masked, paired comparison with vehicle-placebo solution study. Arch Ophthalmol. 1988;106(3):344-347.
42. Flach AJ, Kraff MC, Sanders DR, Tanenbaum L. The quantitative effect of $0.5 \%$ ketorolac tromethamine solution and $0.1 \%$ dexamethasone sodium phosphate solution on postsurgical blood-aqueous barrier. Arch Ophthalmol. 1988;106(4):480-483.

43. Flach AJ. The incidence, pathogenesis and treatment of cystoid macular edema following cataract surgery. Trans Am Ophthalmol Soc. 1998;96:557-634.

44. Efficacy of diclofenac eyedrops in preventing postoperative inflammation and long-term cystoid macular edema. Italian Diclofenac Study Group. J Cataract Refract Surg. 1997;23(8):1183-1189.

45. Roberts CW, Brennan KM. A comparison of topical diclofenac with prednisolone for postcataract inflammation. Arch Ophthalmol. 1995;13(6):725-727.

46. Simone JN, Pendelton RA, Jenkins JE. Comparison of the efficacy and safety of ketorolac tromethamine $0.5 \%$ and prednisolone acetate $1 \%$ after cataract surgery. J Cataract Refract Surg. 1999;25(5):699-704.

47. Missotten L, Richard C, Trinquand C. Topical $0.1 \%$ indomethacin solution versus topical $0.1 \%$ dexamethasone solution in the prevention of inflammation after cataract surgery. The Study Group. Ophthalmologica. 2001;215(1):43-50.

48. Mirshahi A, Djalilian A, Rafiee F, Namavari A. Topical administration of diclofenac (1\%) in the prevention of miosis during vitrectomy. Retina. 2008;28(9):1215-1220.

49. Cho H, Wolf KJ, Wolf EJ. Management of ocular inflammation and pain following cataract surgery: focus on bromfenac ophthalmic solution. Clin Ophthalmol. 2009;3:199-210.

50. Bucci FA Jr, Waterbury LD. Prostaglandin e(2) inhibition of ketorolac $0.45 \%$, bromfenac $0.09 \%$, and nepafenac $0.1 \%$ in patients undergoing phacoemulsification. Adv Ther. 2011;28(12):1089-1095.

51. Takamatsu F, Shiroyama N, Saito Y, Ichikawa S. Efficacy and adverse effects of bromfenac ophthalmic solution following cataract surgery. Rinsho Ganka Jpn J Clin Ophthalmol. 2003;57(7):1233-1237. Japanese.

52. Ohara K, Okubo A, Miyamoto T, Miyakubo H, Nezu N, Matsuda A. Effect of bromfenac sodium on postoperative inflammation. Jpn $J$ Cataract Refract Surg. 2004;18(2):1-12. Japanese.

53. Masuda K, Fukado Y, Shimizu H, et al. Effect of bromfenac sodium ophthalmic solution on inflammation following intraocular lens implantation. Ganka Rinsho Iho (Jpn Rev Clin Ophthalmol). 1997;91:745-750.

54. Miyanaga M, Miyai T, Nejima R, Maruyama Y, Miyata K, Kato S. Effect of bromfenac ophthalmic solution on ocular inflammation following cataract surgery. Acta Ophthalmol. 2009;87(3):300-305.

55. Seward MS CD, Grillone LR, et al. Topical Xibrom ${ }^{\mathrm{TM}} 0.09 \%$, significantly reduced ocular pain following cataract surgery. ARVO Meeting Abstracts. May 1, 2006;47:679.

56. Donnenfeld ED HE, Stewart RH, et al. Topical XibromTM 0.1\% an investigational NSAID, significantly and rapidly decreased post-cataract surgery inflammation and reduced ocular pain. ARVO Meeting Abstracts. May 1, 2005;46:791.

57. Asano S, Miyake K, Ota I, et al. Reducing angiographic cystoid macular edema and blood-aqueous barrier disruption after smallincision phacoemulsification and foldable intraocular lens implantation: multicenter prospective randomized comparison of topical diclofenac $0.1 \%$ and betamethasone $0.1 \%$. J Cataract Refract Surg. 2008;34(1):57-63.

58. Rossetti L, Chaudhuri J, Dickersin K. Medical prophylaxis and treatment of cystoid macular edema after cataract surgery. The results of a meta-analysis. Ophthalmology. 1998;105(3):397-405.

59. Kim SJ, Flach AJ, Jampol LM. Nonsteroidal anti-inflammatory drugs in ophthalmology. Surv Ophthalmol. 2010;55(2):108-133.

60. Hashimoto T, Igarashi A, Hoshina F, et al. Effects of nonsteroidal antiinflammatory drugs on experimental allergic conjunctivitis in Guinea pigs. J Ocul Pharmacol Ther. 2003;19(6):569-577.

61. Miyake-Kashima M, Takano Y, Tanaka M, et al. Comparison of $0.1 \%$ bromfenac sodium and $0.1 \%$ pemirolast potassium for the treatment of allergic conjunctivitis. Jpn J Ophthalmol. 2004;48(6):587-590. 
62. Uchio E, Itoh Y, Kadonosono K. Topical bromfenac sodium for long-term management of vernal keratoconjunctivitis. Ophthalmologica. 2007;221(3):153-158.

63. Sainz de la Maza M, Foster CS, Jabbur NS. Scleritis associated with systemic vasculitic diseases. Ophthalmology. 1995;102(4): 687-692.

64. Frucht-Pery J, Siganos CS, Solomon A, Shvartzenberg T, Richard C, Trinquand $\mathrm{C}$. Topical indomethacin solution versus dexamethasone solution for treatment of inflamed pterygium and pinguecula: a prospective randomized clinical study. Am J Ophthalmol. 1999;127(2): $148-152$.

65. The definition and classification of dry eye disease: report of the Definition and Classification Subcommittee of the International Dry Eye Work Shop (2007). Ocul Surf. 2007;5(2):75-92.

66. Lekhanont K, Park CY, Smith JA, et al. Effects of topical antiinflammatory agents in a botulinum toxin B-induced mouse model of keratoconjunctivitis sicca. J Ocul Pharmacol Ther. 2007;23(1):27-34.

67. Prasher P. Acute corneal melt associated with topical bromfenac use. Eye Contact Lens. 2011. Epub Dec 13.

68. Durrie DS, Kennard MG, Boghossian AJ. Effects of nonsteroidal ophthalmic drops on epithelial healing and pain in patients undergoing bilateral photorefractive keratectomy (PRK). Adv Ther. 2007;24(6):1278-1285.

69. Sher NA, Golben MR, Bond W, Trattler WB, Tauber S, Voirin TG. Topical bromfenac $0.09 \%$ vs ketorolac $0.4 \%$ for the control of pain, photophobia, and discomfort following PRK. J Refract Surg. 2009;25(2):214-220.

70. Wang XJ, Wong SH, Givergis R, Chynn EW. Evaluation of analgesic efficacy of bromfenac sodium ophthalmic solution $0.09 \%$ versus ketorolac tromethamine ophthalmic solution $0.5 \%$ following LASEK or Epi-LASIK. Clin Ophthalmol. 2011;5:1451-1457.

71. Johnson EI, Dunlop ME, Larkins RG. Increased vasodilatory prostaglandin production in the diabetic rat retinal vasculature. Curr Eye Res. 1999;18(2):79-82.

72. Naveh N, Belkin M, Ben-Chaim O, Weissman C, Treister G. Prostanoids in the vitreous of diabetic and nondiabetic human eyes with retinal detachment. Ophthalmic Res. 1990;22(1):3-11.

73. Kern TS, Miller CM, Du Y, et al. Topical administration of nepafenac inhibits diabetes-induced retinal microvascular disease and underlying abnormalities of retinal metabolism and physiology. Diabetes. 2007;56(2):373-379.

74. Amrite AC, Ayalasomayajula SP, Cheruvu NP, Kompella UB. Single periocular injection of celecoxib-PLGA microparticles inhibits diabetesinduced elevations in retinal PGE2, VEGF, and vascular leakage. Invest Ophthalmol Vis Sci. 2006;47(3):1149-1160.
75. Kim SJ, Adams NA, Toma HS, et al. Safety of intravitreal ketorolac and diclofenac: an electroretinographic and histopathologic study. Retina. 2008;28(4):595-605.

76. Bressler NM. Age-related macular degeneration is the leading cause of blindness. JAMA. 2004;291(15):1900-1901.

77. Patel M, Chan CC. Immunopathological aspects of age-related macular degeneration. Semin Immunopathol. 2008;30(2):97-110.

78. Ayalasomayajula SP, Kompella UB. Celecoxib, a selective cyclooxygenase- 2 inhibitor, inhibits retinal vascular endothelial growth factor expression and vascular leakage in a streptozotocin-induced diabetic rat model. Eur J Pharmacol. 2003;458(3):283-289.

79. Yoshinaga N, Arimura N, Otsuka H, et al. NSAIDs inhibit neovascularization of choroid through HO-1-dependent pathway. Lab Invest. 2011;91(9):1277-1290.

80. Flaxel C, Schain MB, Hamon SC, Francis PJ. Prospective randomized controlled trial of combination ranibizumab (lucentis) and bromfenac (xibrom) for neovascular age-related macular degeneration: a Pilot Study. Retina. 2012;32(3):417-423.

81. Zweifel SA, Engelbert M, Khan S, Freund KB. Retrospective review of the efficacy of topical bromfenac $(0.09 \%)$ as an adjunctive therapy for patients with neovascular age-related macular degeneration. Retina. 2009;29(10):1527-1531.

82. Guadagni F, Ferroni P, Palmirotta R, Del Monte G, Formica V, Roselli M. Non-steroidal anti-inflammatory drugs in cancer prevention and therapy. Anticancer Res. 2007;27(5A):3147-3162.

83. Rao CV, Reddy BS. NSAIDs and chemoprevention. Curr Cancer Drug Targets. 2004;4(1):29-42.

84. Souza Filho JP, Martins MC, Correa ZM, et al. The expression of cyclooxygenase 2 in retinoblastoma: primary enucleated eyes and enucleation after conservative treatment. Am J Ophthalmol. 2006;142(4):625-631.

85. de Souza Filho JP, Correa ZM, Marshall JC, et al. The effect of a selective cyclooxygenase-2 (COX-2) inhibitor on the proliferation rate of retinoblastoma cell lines. Eye (Lond). 2006;20(5):598-601.

86. Figueiredo A, Caissie AL, Callejo SA, McLean IW, Gold P, Burnier MN Jr. Cyclooxygenase-2 expression in uveal melanoma: novel classification of mixed-cell-type tumours. Can J Ophthalmol. 2003;38(5):352-356.

87. Marshall JC, Fernandes BF, Di Cesare S, et al. The use of a cyclooxygenase-2 inhibitor (Nepafenac) in an ocular and metastatic animal model of uveal melanoma. Carcinogenesis. 2007;28(9): 2053-2058.

88. Cryan LM, Paraoan L, Hiscott P, et al. Expression of COX-2 and prognostic outcome in uveal melanoma. Curr Eye Res. 2008;33(2): 177-184.
Clinical Ophthalmology

\section{Publish your work in this journal}

Clinical Ophthalmology is an international, peer-reviewed journal covering all subspecialties within ophthalmology. Key topics include: Optometry; Visual science; Pharmacology and drug therapy in eye diseases; Basic Sciences; Primary and Secondary eye care; Patient Safety and Quality of Care Improvements. This journal is indexed on Submit your manuscript here: http://www.dovepress.com/clinical-ophthalmology-journal

\section{Dovepress}

PubMed Central and CAS, and is the official journal of The Society of Clinical Ophthalmology (SCO). The manuscript management system is completely online and includes a very quick and fair peer-review system, which is all easy to use. Visit http://www.dovepress.com/ testimonials.php to read real quotes from published authors. 